Nicolas Berggruen y Nathan Gardels, Gobernanza inteligente para el siglo XXI. Una vía intermedia entre Occidente y Oriente, 2012, Madrid, Editorial Taurus, prol. de Felipe González y de Erneso Zedillo, trad. de Federico Corriente y Miguel Izquierdo, 280 pp.

RECEPCIÓN: 06 de mayo de 2013.

ACEPTACIÓN: 04 de junio de 2013.

\title{
Introducción
}

Nicolas Berggruen, el "multimillonario' sin hogar" ("homeless billionaire"), ${ }^{2}$ dueño de Berggruen Holdings, ${ }^{3}$ nos presenta en el libro Gobernanza inteligente para el siglo XXI. Una vía intermedia entre Occidente y Oriente, una propuesta para solucionar los problemas de Estados Unidos y del mundo mediante la búsqueda, nada nueva, de una postura intermedia. A diferencia del sociólogo inglés Anthony Giddens (autor de The Third Way: The Renewal of Social Democracy, 1998), Berggruen no propone un camino entre la izquierda y la derecha, sino una vía intermedia entre la "democracia consumista" de Estados Unidos y el "mandarinato meritocrático" de China. Es decir, entre la soberanía democrática del pueblo y la perspectiva de largo plazo de las élites, entre Occidente y Oriente.

Le acompaña en esta aventura Nathan Gardels, Media Fellow del World Economic Forum de Davos, editor de New Perspectives Quarterly y fun-

${ }^{1}$ Ocupa el lugar 736 en la lista mundial Forbes y el 249 en el ranking de Estados Unidos en el 2013.

${ }^{2} \mathrm{Se}$ ha nombrado al ciudadano alemán y estadounidense Nicolas Berggruen el "multimillonario sin hogar" en virtud de que el año 2000 decidió vender su lujoso apartamento de Manhattan, así como su casa Art Deco de una isla privada de Miami, para vivir una vida "sencilla" en hoteles de cinco estrellas de Londres, Nueva York y Los Ángeles (y de paso no pagar impuestos). Claro no deja de darse ciertos lujos, como la fiesta al más puro estilo "playboy" que cada año hace en el Chateau Marmont de Hollywood en la semana de la entrega del Oscar. En ella tiene la oporunidad de codearse con Paris Hilton y Leonardo DiCaprio. Cfr. Business Week, "Deep Thoughts With the Homeless Billionaire By Devin Leonard, 27 de septiembre del 2012, http://www.businessweek.com/articles/2012-09-27/deep-thoughts-with-the-homeless-billionaire.

${ }^{3}$ Empresa financiera neoyorquina que ha hecho mucho dinero comprando empresas con problemas. 
cionario (Senior Advisor) del Instituto Nicolás Berggruen, creado por el "multimillonario sin hogar", con el propósito de estudiar sistemas de gobierno que permitan enfrentar mejor los retos del siglo XXI.

Para los autores la democracia, al igual que los mercados, no se corrige por sí misma. El sistema estadounidense de una persona-un voto se dirige a la ruina. La buena gobernanza se logra cuando las instituciones políticas y el sistema económico "se combinan para establecer un equilibrio que genera resultados eficaces y sostenibles en interés común de todos" (p. 42).

No es la primera vez que la democracia es atacada por la aristocracia en Estados Unidos. Alan Wolfe, sociólogo de la Universidad de Yale, nos recuerda que desde el siglo XIX, en ese país las élites se han opuesto a ella por una motivación muy sencilla: mientras más restringida esté la democracia hay una mayor posibilidad de que las élites mantengan sus ventajas logradas de manera injusta. ${ }^{4}$

Para demostrar su tesis, Berggruen y Gardels inician con un mesurado análisis a las formas de gobierno de Estados Unidos, la democracia consumista como los autores le denominan, y la meritocracia China. Resaltan los puntos buenos y malos de cada sistema. No obstante, el equilibrio se pierde poco a poco y terminan mostrándose claramente a favor del modelo chino; hasta el capítulo cuarto, los autores muestran sus cartas:

Como sostendremos más adelante y con frecuencia en este libro, la democracia electoral una-persona-un-voto está actualmente en crisis porque el interés a corto plazo manifestado por el votante individual, al no estar filtrado por poderosas instituciones deliberativas que ahora están desgastadas, no es colectivamente equiparable a los intereses comunes de largo plazo. En las urnas, la racionalidad al por menor puede dar paso fácilmente a la locura al por mayor (p. 134).

\section{La globalización}

En la línea del pensamiento económico dominante, los autores afirman que la "globalización 1.0", "neoliberal" y dirigida por Estados Unidos, provocó el crecimiento de los países de la periferia. La mayor circulación de mercancías y capitales, así como de información y tecnología, ha dado paso a una nueva fase: la "globalización 2.0". Este desplazamiento de poder plantea

${ }^{4}$ Cfr. Alan Wolfe, Does American Democracy Still Work?, 2006, New Haven, Yale University Press. 
un serio reto de gobierno, tanto al interior de cada país como a nivel internacional. A China le hace falta un "mandarinato más responsable" y a Estados Unidos una "democracia más despolitizada". En palabras de los autores: "En resumen, China debería aflojar y Estados Unidos debería apretar” (p. 47).

Ciertamente, y para lograr un poco de equilibrio, los autores reconocen que este proceso globalizador no ha estado exento de problemas. En Estados Unidos provocó un pérdida en los niveles de bienestar de los sectores medios, mientras que China traza un camino hacia la transición de la clase media. En los países ricos abundan los pobres y en los países pobres abundan los ricos.

\section{Democracia consumista estadounidense y mandarinato moderno chino}

Berggruen y Gardels afirman que ha llegado el momento de reexaminar a la democracia por dos razones: a) el éxito continuado de formas de modernidad no occidental, por ejemplo Singapur o China; $y, b$ ) porque Occidente ha cambiado.

Para los autores, los sistemas democráticos están diseñados para dar a la mayoría lo que quiere, cuando lo quiere. Los estadounidenses quieren libertad y felicidad, es decir, desean consumir; las elecciones del consumidor son a corto plazo y egoístas, eclipsan cualquier perspectiva de largo plazo y del bien común. La política se ha puesto al servicio de este pensamiento de la "gratitud inmediata". A todo esto hay que sumar el poder y los intereses de corto plazo de los grupos de presión. En una democracia consumista, "la capacidad política para postergar disciplinadamente la gratificación inmediata y pensar y planificar a largo plazo escasea, al igual que la continuidad de la gobernanza que va asociada a todo ello" (p. 71).

Los autores olvidan que los grupos de presión financieros, representados por élites "eficaces y aristocráticas", tuvieron una visión de largo plazo cuando ingresaron al gobierno de Ronald Reagan y propusieron, por el bien de todos los estadounidenses, desregulaciones financieras que terminaron provocando la crisis financiera del 2008.

Para los autores, el problema fiscal y de endeudamiento en Estados Unidos (ponen como ejemplo el estado de California) se da por la combinación de los intereses de los grupos de presión y la mentalidad cortoplacista de los votantes. Los autores hacen eco del artículo de The Economist sobre el estado 
de California, titulado "Democracy in California. The people's will". La revista afirma que los problemas que enfrenta el estado, producto de la crisis del 2008 , no tienen nada que ver con "viviendas, ejecuciones o acciones de Internet". Tampoco es culpable ninguno de los gobernadores que el estado ha tenido. El problema es la democracia: el referéndum, las iniciativas ciudadanas y la revocación de mandato. ${ }^{5}$

¿No será más bien que la disputa tiene que ver con "quién paga los platos rotos"?, me pregunto. Las élites desean pasar factura a la sociedad; y ésta reacciona en consecuencia. Me parece que la democracia no le ayuda a las élites, que se han enriquecido en los últimos años, a implantar medidas que atenten contra el bienestar de los sectores medios y pobres.

Regresemos al desarrollo de la tesis de los autores. Para Berggruen y Gardels, todo esto contrasta agudamente con la situación de China, en donde el gobierno está invirtiendo intensamente en su futuro, como lo hicieron California y Estados Unidos en los años cincuenta y sesenta. Si bien los autores reconocen que el modelo chino tiene problemas graves, la gobernanza ha permitido que el país avance. Por ello, plantean:

La cuestión de si las democracias occidentales, consumistas, fragmentadas y endeudadas, maniatadas por sus costumbres culturales y su horizonte político cortoplacista, se están volviendo ingobernables en el mismo momento en que el liderazgo autoritario unificado y previsor chino, pese a los enormes desafíos a los que se enfrenta, está llevando a su país de forma audaz y decidida hacia el futuro (p. 75).

En un intento de mantener un cierto equilibrio, reconocen que el sistema político chino requiere una prensa más libre, así como de la institucionalización del imperio de la ley y una mayor responsabilidad de los cargos públicos ante sus electores. Sin embargo, inmediatamente concluyen afirmando que China "es una sociedad bastante menos cerrada de lo que cree la mayor parte de los occidentales". Y agregan que el "mandarinato moderno" chino es meritocrático y está orientado hacia el progreso común del país en su conjunto. Sólo le falta orientar sus políticas hacia una mayor apertura, crear mecanismos de control de responsabilidades y atender los intereses de la creciente clase media urbana.

${ }^{5}$ Cfr. The Economist, "Democracy in California. The people's will”, 20 de abril del 2011. 


\section{Las redes sociales}

Los autores muestran preocupación por el poder que ha conseguido el ciudadano en las redes, ya que este poder resta capacidad de maniobra al gobierno:

La aparición de las redes sociales ha cambiado las reglas de juego de la gobernanza. Tanto para Estados Unidos como para China, la evolución de la democracia también supone forzosamente averiguar cómo equilibrar el robusto poder de participación de las redes sociales con la autoridad de gobierno legítima que se requiere para ocuparse del bien común y de los intereses de la comunidad a largo plazo (p. 125).

Reconocen que "en ningún lugar salta tanto a la vista este desplazamiento de poder como en China". Sin embargo, el que "aficionados como nosotros" (así denominan a los ciudadanos y los movimientos que se han apoyado de la red para la consecución de sus objetivos), hayan ganado poder más allá y en contra de las élites y de las instituciones mediadoras, no es un buen síntoma: "Sin frenos ni contrapesos, la democracia directa propulsada por la energía del ciberespacio podría socavar la buena gobernanza en lugar de reforzarla" (p. 135).

Se debe transformar, de acuerdo a los autores, la "necia multitud" en "multitud inteligente". ¿Cómo? Mudando los procesos deliberativos del ciberespacio a grupos ad hoc de expertos. Se requiere buscar un equilibrio entre "Facebook y el Partido": "Es una ilusión libertaria creer que redes distribuidas de aficionados o de 'expertos desconocidos' puedan administrar ellas solas una sociedad basada en decisiones racionales fundadas en el interés particular" (p. 141).

De hecho, los autores llegan al punto de afirmar que las redes fueron las causantes de la crisis financiera del 2008; pero no las redes ciudadanas en Internet, sino que "fueron redes distribuidas de expertos [¿aficionados?] financieros las que instigaron al colapso de Wall Street". La solución:

Un nuevo modelo 'híbrido' de gobernanza que haga sitio para la complejidad de unos participantes más diversificados mediante estructuras jerárquicas dotadas de autoridad y de capacitad, más procesos de creación de consenso y, al mismo tiempo, un mayor número de mecanismos de crítica constructiva para garantizar la transparencia mutua (p. 142). 
Los autores no aclaran cómo distinguir la crítica constructiva de la presión política, ni cómo llegar a la objetividad del conocimiento económico social y político sobre el quehacer diario, libre de posturas ideológicas.

\section{La propuesta}

Poco a poco los autores nos permiten ver la dimensión de su propuesta. Un primer aspecto que sugieren es elevar al poder a los que son dignos de ocupar puestos de responsabilidad. Son claros al afirmar que no proponen terminar con la democracia una persona-un voto y transferir la soberanía a una élite meritocrática. Pero les preocupa la "vetocracia". La solución: una democracia despolitizada: instituciones deliberativas que defiendan públicamente la legitimidad de sus decisiones y que roten a su personal. Estas instituciones deben tener "cierta opacidad" para proteger sus decisiones de la presión popular y de la tiranía de la mayoría. En palabras de los autores: "La opacidad proporciona un margen para la deliberación razonada no sujeta a la opinión popular" (p. 99).

La democracia deliberativa no parte del supuesto de que el electorado en su conjunto elegirá a los mejores líderes, y en su lugar crea la oportunidad para que los votantes elijan las mejores políticas que han sido estudiadas de manera deliberativa. En pocas palabras, es una especie de medida intermedia que traslada la carga del conocimiento en materia de gobernanza del votante medio al votante 'indicativo' deliberante (p. 118).

Los autores proponen una "pragmatismo post-ideológico", en donde la democracia no es más que un medio para llegar al fin: la buena gobernanza.

Muy probablemente ha llegado a la mente de alguno de los lectores "El Pacto por México", firmado por el presidente y los dirigentes de los tres principales partidos políticos. Nathan Gardels fue invitado a la toma posesión de Enrique Peña Nieto. En un artículo publicado por el periódico español El País, Gardels critica duramente a los gobiernos “populistas", es decir, a todos aquellos que no han seguido al pie de la letra el dictado del Washington Consensus (sólo se salvan de su diatriba Colombia, México y Chile, al que denomina el Singapur del hemisferio Occidental); Gardels elogia que Peña Nieto haya terminado con "los resentimientos partidistas al anunciar un pacto de consenso". ${ }^{6}$ Curiosa coincidencia.

${ }^{6}$ Cfr. Nathan Gardels, "Latinoamérica y la tentación populista", El País, 11 de abril del 2013. 
Para Berggruen y Gardels "se debe respetar el derecho de los ciudadanos a decir todo lo que les parezca a nivel local, allí donde viven y trabajan". Pero los ciudadanos deben respetar a los "competentes y virtuosos" que lleven las riendas del gobierno, en los niveles más altos:

La mejor Constitución Política de un Estado y su forma de gobierno es aquella que, con la seguridad más natural, lleva a situaciones de importancia preponderante y de influencia directriz a los más calificados elementos de la comunidad nacional.

Le he jugado una mala pasada al lector; esta cita no es del libro que estoy reseñando. Mil disculpas. La he tomado de Adolfo Hitler, Mi lucha. ${ }^{7}$ Permítanme otra travesura, en otro párrafo el mismo autor afirma:

Una ideología (Weltanschauung) que, rechazando el principio democrático de la masa, aspira a consagrar este mundo en favor de los mejores, es decir, del hombre superior, está lógicamente obligada a reconocer también el principio aristocrático de la selección dentro de cada Nación, garantizando así el gobierno y la máxima influencia de los más capacitados en sus respectivos pueblos. ${ }^{8}$

Al igual que Berggruen y Gardels, Hitler deseaba liberar al gobierno de la tiranía de la mayoría: "El Estado Nacionalista debe trabajar infatigablemente para liberar al Gobierno, sobre todo en los altos cargos de la dirección, del principio parlamentario de la mayoría, para asegurar, en su lugar, la indiscutible autoridad del individuo".

Pero no exageremos. Ciertamente Berggruen y Gardels no desean llegar $\tan$ lejos. Al menos eso espero. Proponen que aquellos que moran en la cima "deben poseer no sólo la pericia técnica requerida, sino también la sabiduría práctica de la experiencia y el conocimiento de los precedentes históricos. Deben, efectivamente, constituir una meritocracia avisada". Es decir, deben ser prudentes, discretos y sagaces. Ojalá así sea, pues de lo contrario nos esperan momentos muy oscuros.

Aislada de las presiones inmediatas de la democracia electoral, el cuerpo meritocrático debe "oxigenarse regularmente a fin de no anquilosarse". Debe,

${ }^{7}$ Cfr. Adolfo Hitler, Mi lucha, t. II, cap. IV.

${ }^{8}$ Ibidem. A Hitler también le preocupaba la estrechez de miras de los partidos políticos: "Mientras que el programa de un partido netamente político no es más que una receta para el buen resultado de las próximas elecciones, el Programa de una concepción ideológica representa la fórmula de una declaración de guerra contra el orden establecido, contra el estado de cosas existente; en fin, contra el criterio dominante de la época" (op cit., cap. V). 
además, ser supervisado por los "grupos de presión" y por los representantes democráticamente elegidos que le delegan la autoridad. La democracia constitucional resultante estaría dividida en los siguientes "brazos independientes":

a) Legislativo. Que tendría una cámara baja con representantes nombrados por delegados locales (los delegados locales serían electos por voto directo de los ciudadanos), y una cámara alta electa por el presidente, la cámara baja y la tetrarquía;

b) Ejecutivo nombrado por la mayoría de la cámara baja;

c) Una tetrarquía presidencial conformada por cuatro miembros distinguidos y veteranos hombres de Estado que representen al conjunto de la sociedad, nombrados por el presidente y sancionados por la cámara baja. Entre sus facultades estaría la de convocar a un referéndum para "habilitar al electorado en su conjunto a fin de que expresara su aprobación o desacuerdo sobre políticas clave de gobierno";

d) Poder judicial;

e) Banco central;

f) Agencia de Recursos Humanos, encargada de reclutar, examinar, colocar, reciclar y supervisar la actuación del personal administrativo. Los altos miembros de esta agencia serían nombrados por la cámara alta y sancionados por la baja;

g) Oficina de Integridad Gubernamental, nombrada por el director de la Agencia de Recursos Humanos y sancionada por la cámara alta. Su encargo sería supervisar la actuación y rectitud de los legisladores, el presidente y de las instituciones administrativas.

El título del último capítulo lo dice todo: "La supervivencia de los más sabios". No precisa más comentarios.

\section{Conclusión}

De un diagnóstico erróneo es muy probable que surja una solución inadecuada. La "globalización 1.0", como la nombran los autores, ha provocado un incremento del hambre y la pobreza en el mundo. El aumento de la clase media en China y en los países desarrollados es un mito. El "crecimiento de los demás" está lejos de ser realidad. 
Como demostraron el sociólogo Philip Slater y el "gurú" de la administración Warren Bennis, la democracia es la mejor forma de gobierno que permite a una organización humana enfrentar la complejidad y el cambio. El autoritarismo "ilustrado" genera burocracia e ineficiencia. ${ }^{9}$

La probabilidad de que una élite meritocratica (autonombrada "ilustrada") se equivoque es mayor, o en el mejor de los casos, igual a que los ciudadanos (denominados "masa caótica") se equivoquen. No obstante, hay una ventaja en el enfoque democrático. Los ciudadanos pueden aprender de sus errores, las élites meritocráticas rara vez aprenden de sus desaciertos, ya que no los sufren. Como nos dice Slater:

A menudo los autoritarios objetan que la democracia significa dar a las personas lo que quieren, y por regla general las personas quieren lo que no es bueno para ellos. El enfoque democrático a este problema es permitir a las personas aprender lo que no es bueno para ellos por medio de sus propios errores. La solución autoritaria es dar poder absoluto a una de estas personas que no saben lo que es bueno para ellos de manera que pueda imponer su propia marca peculiar de ignorancia sobre todos los demás. ${ }^{10}$

\section{Y más adelante agrega:}

Bajo nuestro sistema actual, los líderes rara vez sufren los resultados de su propia estupidez; las desgracias descienden a la población en su conjunto, o sobre los sectores más indefensos, los soldados que son asesinados, los trabajadores envenenados, los pobres que se hacen más pobres. Los líderes autoritarios están aislados por su posición de las consecuencias de su locura. ${ }^{11}$

Todo esto me lleva a pensar que, en el fondo, lo que estamos viviendo es una toma de poder por parte de las élites y la aristocracia financiera. El modelo económico y político global imperante ha producido enormes desigualdades. De ahí se deriva el problema de la "gobernanza". Las élites se han dado cuenta de que no es posible sostener este modelo, no sustentable desde el punto de vista humano ni ecológico, sin un retroceso autoritario, endulzado con una postura meritocrática.

${ }^{9}$ Cfr. Philip Slater y Warren Bennis, "Democracy is inevitable", Harvard Business Review, marzoabril, 1964, .

${ }^{10}$ Philip Slater, A dream deferred. America's discontent and the search for a new democratic ideal, 2001, Boston, Beacon Press, p. 20.

${ }^{11}$ Ibid., p. 21. 
El giro autocrático requiere un análisis en donde se cambia el énfasis. El problema no fue ni es económico; el modelo imperante es correcto, afirman. Ha producido bienestar y clase media en todo el mundo. Si se ha cometido algún error, es en lo político. Hay que encontrar un culpable. Para los autores, en Estados Unidos es la polarización de los partidos y la ignorancia del ciudadano consumista; algunos analistas agregan al inmigrante mexicano.

En otros países la situación es aún más crítica. En Grecia, por ejemplo, la ultraderecha culpa a los inmigrantes y a los políticos incompetentes y corruptos del desastre económico neoliberal. La solución: crear un partido neonazi "Amanecer Dorado", que obtuvo el 7\% de los votos y 21 diputados en las elecciones pasadas. Para su líder, Mijaloliakos, Adolfo Hitler es el "Gran Hombre del siglo XX; apóstol de la revolución nacionalsocialista y de la cruz gamada". ${ }^{12}$ Silvio Berlusconi no tiene empacho en decir que Mussolini hizo cosas buenas por Italia. ${ }^{13}$

Bien valdría la pena recordar la historia, para no sufrir de nuevo las consecuencias de una nueva oleada de autoritarismo en el mundo, encabezada por élites que se asumen como ilustradas.

\section{MIGUEL DEL CASTILLO NEGRETE} Departamento Académico de Estudios Generales Instituto Tecnológico Autónomo de México

${ }^{12}$ Cfr. María Antonia Sánchez-Vallejo, “Cuidado: fascistas sueltos”, El País, 22 de abril de 2012.

${ }^{13} \mathrm{Cfr}$. Pablo Ordaz, "Berlusconi dice que Mussolini hizo cosas buenas en Italia. El ex primer ministro italiano realiza estas declaraciones en la Jornada de la Memoria de las Víctimas del Holocausto", El País, 27 de enero del 2013. 